\title{
Study on a Novel Filter Media Incorporating with Core Shell Nanoencapsulated Phase Change Material: Fabrication and Evaluation
}

\author{
Chi Zhang ${ }^{1,2,3,4, *}$, Shuo Chang ${ }^{3}$, Gaoju Song ${ }^{2}$, Jianlin Liu ${ }^{1,4, *}$ and Henggen Shen ${ }^{1,4}$ \\ 1 College of Environmental Science and Engineering, Donghua University, Shanghai 201620, China; \\ Shenhg@dhu.edu.cn \\ 2 Sippr Engineering Group Co., Ltd., Zhengzhou 450007, China; 13838135839@163.com \\ 3 College of Materials and Textile Engineering, Jiaxing University, Jiaxing 314001, China; \\ changshuo@zjxu.edu.cn \\ 4 Institute of Heating, Ventilation and Air Conditioning, Donghua University, Shanghai 201620, China \\ * Correspondence: zhangchi@mail.dhu.edu.cn (C.Z.); jianlin.liu@dhu.edu.cn (J.L.); \\ Tel.: +86-573-8364-0471 (C.Z.); +86-21-6779-2625 (J.L.)
}

check for updates

Citation: Zhang, C.; Chang, S.; Song, G.; Liu, J.; Shen, H. Study on a Novel Filter Media Incorporating with Core Shell Nanoencapsulated Phase Change Material: Fabrication and Evaluation. Processes 2021, 9, 731. https://doi.org/10.3390/pr9050731

Academic Editor: Urszula Bazylinska

Received: 22 February 2021

Accepted: 20 April 2021

Published: 21 April 2021

Publisher's Note: MDPI stays neutral with regard to jurisdictional claims in published maps and institutional affiliations.

Copyright: (c) 2021 by the authors. Licensee MDPI, Basel, Switzerland. This article is an open access article distributed under the terms and conditions of the Creative Commons Attribution (CC BY) license (https:// creativecommons.org/licenses/by/ $4.0 /)$.

\begin{abstract}
Thermal performance of filter media plays a significant effect on the filtration efficiency of baghouse, especially its tolerance of high temperature air and chemical erosion. In this study, nano-encapsulated phase change material within the silica shell (NPCMs) is synthesized through a self-assembly method based on polymer-hyperbranched precursor polyethoxysiloxane (PEOS). Filter media is fabricated by NPCMs through a facile dip-dry-cure process to enhance its thermal regulation and serving durability. Filter media acts as frame-supporting of the functional structure NPCMs. Incorporating NPCMs into filter media optimizes the microstructure and filtration efficiency of baghouse. The penetration rate was reduced from $457 \times 10^{-4} \%$ of the control filter media to $5 \times 10^{-4 \%}$. Meanwhile, the novel filter media lowers the temperature up to $20{ }^{\circ} \mathrm{C}$ than the surroundings. The novel filter media exhibits not only better mechanical properties, but also much less tensile strength loss after suffering 100 thermal shock cycles with simultaneous chemical exposure, from $37.58 \%$ to $20.37 \%$. Overall, the filter media incorporated with NPCMs demonstrates excellent performances on filter efficiency, thermal regulation, and environmental endurance, which has the potential for extending lifespans and enhancing operation stability of filter bags in industrial air pollutant control.
\end{abstract}

Keywords: industrial air pollutant dispersion; nano-encapsules; phase change material; filter media performance; thermal regulation; environmental endurance

\section{Introduction}

In recent years, flue gas emissions discharged from coal-fired power plants, steel works, and foundry industries have been significantly increased, which have led to a severe environment and health issues. In order to overcome these problems, baghouse with filter media has been employed in flue gas treatment due to high particles collection efficiency, which can meet the requirements of air pollutant dispersion and health consciousness in national standards [1-5]. In most cases, polyester (PE) non-woven fabric is currently popular filter media in processing the flue gas of waste incinerator facilities and coal-fired power plants, owing to its low cost, ease of availability, and excellent chemical, thermal, and mechanical properties. However, conventional PE filter media suffered from the gradual deterioration of the mechanical and chemical properties during the lifetime. Flue gas discharged from industrial manufacturing containing fine particles and corrosive gases $\left(\mathrm{NO}_{\mathrm{x}}, \mathrm{SO}_{\mathrm{x}}\right.$, and $\left.\mathrm{Cl}_{2}\right)$ is one important cause of PE degradation [6,7], and the thermal shock caused by an instantaneous super-high temperature flue gas is another one. In addition, 
the relatively low filter efficiency of conventional PE filter media should be mentioned because of the large pore size of micro-sized fibers.

Several strategies, such as electrospun nanofibrous [8] and hierarchical structures filters [9], have partly enhanced the filtration efficiency. However, these are challenging to poor mechanical resistance during a large air flow. This is ascribed to the submicron fiber diameters and the harsh working environment. Besides, composite filters with nanoparticles have been designed to improve the mechanical performance [10], photocatalysis [11], and anti-bacterial [12]. To the best of our knowledge, no extensive studies have been reported on filter media with combined thermal regulation, chemical resistance, and high particulate removal efficiency. Therefore, a new strategy is urgently desired to develop a novel filter media to extend its lifespan and stability under industrial air pollutant control.

Integrated with phase change material (PCM) on filter media would be a good idea for a novel filter media. PCM can absorb, store, and release thermal energy in the form of latent heat during the phase transition to achieve temperature control [13], which has attracted increasing interest in energy-saving building [14-16], solar energy storage installation [17,18], and thermal regulated textile [19-22]. Assembling PCM on the materials' surface could regulate temperature, reduce the apparent temperature swing, and enhance thermal resistance. Simultaneously, the new surface of filter media covering by PCM would benefit particles removal due to the particles' capture mechanism of fibers. However, it is difficult to simply immobilize PCM on the material surface due to mutual changes in phase states between liquid and solid. Encapsulation of PCM is the solution to the issue of leakage during the phase change and better thermal performance and durability can be achieved. PCM microcapsules are generally composed of the PCM core and organic polymer or inorganic container shell. Organic polymers are generally considered good shell materials for encapsulating the PCM core [23-25]. However, they are unsuitable for integrating with filter media due to poor thermal stability, flammability, and toxicity under an acidic, high-operating temperature [26,27]. In terms of encapsulating PCM for filter media, silica is an ideal inorganic shell material due to inertness, heat resistance, mechanics stability, non-poison, and low-cost [28-30]. Only a few studies have been conducted for the core shell nano-encapsulation of PCM, resulting in phase change encapsulated silica material by in-situ sol-gel process [31]. Hyperbranched polyethoxysiloxane (PEOS), which is a highly hydrophobic liquid, is a silica precursor polymer [32]. In our recent research, PEOS would hydrolyze to amphiphilic polymers in water and exhibit interfacial active at the oil/water interface with no auxiliaries $[33,34]$. It provides a possible facile way to encapsulate PCM with nano-silica shell (NPCMs) by a self-assembly method in mini-emulsion. Until now, relevant research studies have very little reported about NPCMs fabricated novel filter media with thermal regulation and environmental endurance.

In this paper, we present a fabrication method of the novel filter media with NPCMs by facile dip-dry-cure process. NPCMs based on PEOS are synthesized in one-pot through a self-assembly method in mini-emulsion without surfactant. Afterward, conventional PE filter media with low cost and excellent mechanical performance is integrated with NPCMs. This study aims to propose a new facile and effective method to construct filter media with superior properties in thermal regulation performance, chemical resistance, and filtration performance. It illustrates the potential application in protecting PE filter media under an accidental production process, where the instantaneous sharp flue gas temperature fluctuation lasts for a few seconds to tens of seconds.

\section{Materials and Methods}

\subsection{Materials}

Tetraethoxysilane (TEOS, Sigma-Aldrich (St. Louis, MO, USA)), acetic anhydride ( $\geq 98.0 \%$, Sinopharm (Beijing, China)), and titanium trimethylsiloxide (ABCR) were used for preparing hyper-branched polyethoxysiloxanes (PEOS). N-docosane $(99 \%)$ was purchased from TCI (Shanghai) Development Co., Ltd. Waterborne polyurethane was obtained from Shanghai Ruiqi Chemical Co., Ltd. Sodium bicarbonate was purchased from Sinopharm 
Chemical Reagent Co., Ltd. Deionized water of Milli-Q grade was used for all experiments. All of the chemical reagents were used without further purification. Polyester filter media $\left(550 \mathrm{~g} / \mathrm{m}^{2}, 5.18 \mathrm{~cm}\right)$ were supplied by Wilkie Technical Textiles (Jiaxing, China) Co., Ltd. PEOS was prepared according to the guidelines in the literature [32].

The obtained PEOS had the following characteristics: degree of branching $0.54, \mathrm{SiO}_{2}$ content $49.2 \%, M_{n} 1740$, and $M_{w} / M_{n} 1.9$ (measured by gel permeation chromatography in chloroform with an evaporative light scattering detector calibrated using polystyrene standards).

\subsection{Apparatus}

Field emission scanning electron microscopy (FE-SEM) was carried out by a Hitachi S-4800. Transmission electron microscopy (TEM) was Hitachi H800. Fourier transformation infrared (FTIR) spectra was obtained using a Nicolet 6700. A thermogravimetric analysis (TGA) measurement was carried out by Netzsch STA449 F3. Differential scanning calorimetry (DSC) was performed using a Netzsch DSC 204F1 differential scanning calorimeter. The PMI capillary flow porometer was model CFP-1100AX and the repeatability error of the measuring system is less than $1 \%$. The universal testing machine from Tinius Olsen was model H5KS with a measuring accuracy of $0.5 \%$. The thermal imaging camera was FLIR E40 with infrared thermography with an accuracy of $0.05 \%+0.3^{\circ} \mathrm{C}$. The thermostatic plate was ETOOL ET-150 with an accuracy of $\pm 1 \sim 2 \%{ }^{\circ} \mathrm{C}$.

\subsection{Synthetic Procedures of Nanoencapsuled Phase Change Material with Silica Shell (NPCMs)}

PCM (n-docosane, $0.5 \mathrm{~g}$ ) was added in deionized water $(10 \mathrm{~mL})$ and heated to $60{ }^{\circ} \mathrm{C}$ until complete melting of PCM. Then, PEOS (0.5 g) was added and the mixture was emulsified by ultrasonic irradiation for $15 \mathrm{~min}$ at $60^{\circ} \mathrm{C}$ (Scientz 650E, $6 \mathrm{~mm}$ microtip, and 1.0 time circle, $227 \mathrm{~W}$ output). Afterward, the emulsion was stirred gently at $60{ }^{\circ} \mathrm{C}$ for $24 \mathrm{~h}$. PCM nano-capsules (NPCMs) were isolated by centrifugation and rinsing 3 times with water, and then re-dispersed in water or dried by freezing-drying for a further measurement. The pure hollow silica nano-capsules (pHSNCs) were obtained by calcining the freezing-dried sample in a muffle oven at $500{ }^{\circ} \mathrm{C}$ for $2 \mathrm{~h}$.

\subsection{Fabrication of Filter Media with NPCMs}

Filter media was incorporated with NPCMs by a dip-dry-cure process, as shown in Figure 1. NPCMs was added into polyurethane emulsion $(100 \mathrm{~g} / \mathrm{L})$ with a $\mathrm{pH}$ adjustment of 7-8 by saturated $\mathrm{NaHCO}_{3}$ solution and the NPCMs suspension was ultrasonicated for $30 \mathrm{~min}$. PE filter media was dipped into the suspension until the suspension was sucked up completely. Then the samples were dried at $90{ }^{\circ} \mathrm{C}$ for $3 \mathrm{~min}$ and cured at $120{ }^{\circ} \mathrm{C}$ for 3 min. A different weight ratio of NPCMs to filter media was utilized and 10\%, 20\%, and 30\% were labelled as FM_NPCMs10, FM_NPCMs20, and FM_NPCMs30, respectively. Additionally, the original filter media was labelled as FM, and the filter media was treated with polyurethane emulsion that was labelled as FM_PU. 

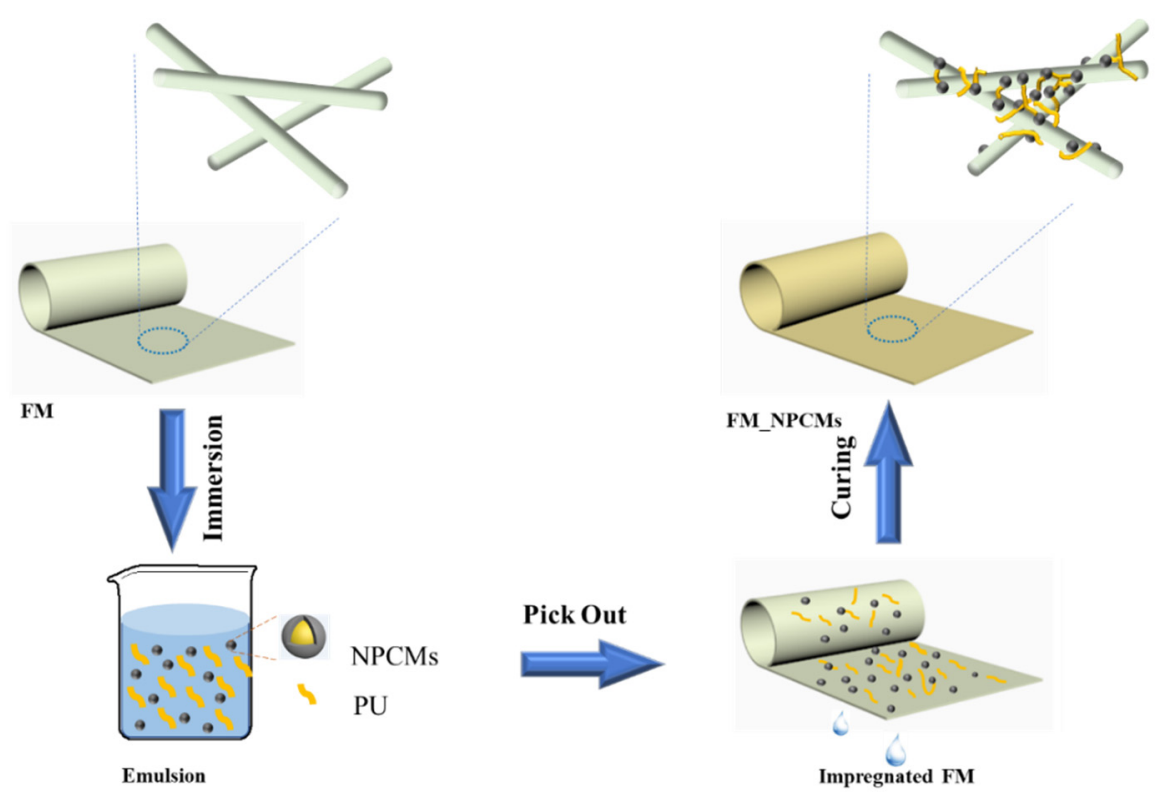

Figure 1. Illustrating the fabrication of a novel filter media with NPCMs.

\subsection{Characterization}

Field emission scanning electron microscopy (FE-SEM) and transmission electron microscopy (TEM) were used for morphological and microstructure characterization. The Nano measure software was used to calculate the particle size distribution and the shell layer thickness.

Fourier transformation infrared spectroscope (FT-IR, spectra from 400 to $4000 \mathrm{~cm}^{-1}$ with a resolution of $4 \mathrm{~cm}^{-1}$ using $\mathrm{KBr}$ pellets) was used to analyze the chemical compositions. Thermogravimetric Analysis (TGA) was employed to investigate the thermal stability and degradation profiles of NPCMs under a nitrogen atmosphere and a heating rate of $10{ }^{\circ} \mathrm{C} / \mathrm{min}$ from room temperature to $800{ }^{\circ} \mathrm{C}$. Differential scanning calorimetry (DSC) was conducted to characterize the latent heat storage behaviors of samples under a nitrogen atmosphere at a heating or cooling rate of $10^{\circ} \mathrm{C} / \mathrm{min}$ with a sample weight of around $5-10 \mathrm{mg}$.

The thermal regulation of the resulting novel filter media was evaluated by infrared thermography and thermal imaging camera with a setting emissivity $(\varepsilon)$ of 0.90 . The specimens were cooled to room temperature $\left(20^{\circ} \mathrm{C}\right)$ and then put on a thermostatic plate keeping at $100^{\circ} \mathrm{C}$. To acquire the temperature distribution, the infrared camera was used to record IR radiation images, where each pixel corresponded to a temperature value. The temperature change during the heating process was taken at different times ranging from 20 to $100{ }^{\circ} \mathrm{C}$. All of the specimens were treated by 100 thermal shock cycles with simultaneous chemical exposure before being investigated by the temperature-regulated properties. The thermal shock cycle with simultaneous chemical exposure was conducted as follows: the specimen covered the hot plate with a temperature elevated from room temperature $\left(20^{\circ} \mathrm{C}\right)$ to $100{ }^{\circ} \mathrm{C}$ in $90 \mathrm{~s}$ and then taken off to cool down to room temperature. During each thermal shock cycle, sulfuric acid solution (2M) was sprayed on the specimen continuously. Ten specimens were employed to test the stability and repeatability of the thermoregulating capacity.

The mechanical properties of the filter media before and after the thermal shock cycle with simultaneous chemical exposure were evaluated using universal testing machines (H5KS, Tinius Olsen Company, (Horsham, PA, USA)), according to a Chinese National Standard GB/T 24218.18. The samples were measured before and after suffering from 100 thermal shock cycles, chemical exposure, or even 100 thermal shock cycles with simultaneous chemical exposure, respectively. The tested samples were cut to dimensions of 
$100 \times 75 \mathrm{~mm}^{2}$. The tensile speed rate was $300 \mathrm{~mm} / \mathrm{min}$ and, for every sample, an average value of five replicates was adopted.

The pore size of filter media was measured using the bubble-point method with a capillary flow porometer. Three specimens for each filter and ten tests per specimen were analyzed.

The penetration rate was evaluated with sodium chloride aerosol particles by an automated filter tester based on a modified Chinese National Standard GB/T 6165, where relative humidity and temperature were about $25 \%$ and $20{ }^{\circ} \mathrm{C}$, respectively. Sodium chloride aerosol particles were fabricated by an aerosol particle generator. The particle size range was 30 300 nm (mass mean diameter: $190 \mathrm{~nm}$, count median diameter: $55 \mathrm{~nm}$ ). The particles were fed into a filter holder and through the filter with an effective area of $20 \mathrm{~cm}^{2}$. The upstream and downstream of the filter were under an air flow of $3.5 \mathrm{~m}^{3} / \mathrm{h}$. The particle-size distributions were measured at the center of the tunnel cross-section, with a sampling probe approximately located $20 \mathrm{~cm}$ before the fabric set on the penetration cell and $10 \mathrm{~cm}$ after the fabric, respectively. Three specimens for each filter and 20 sets of data per specimen collected in equal intervals of time during 2 min were analyzed. The filtration system for the penetration rate testing was shown in Figure 2.

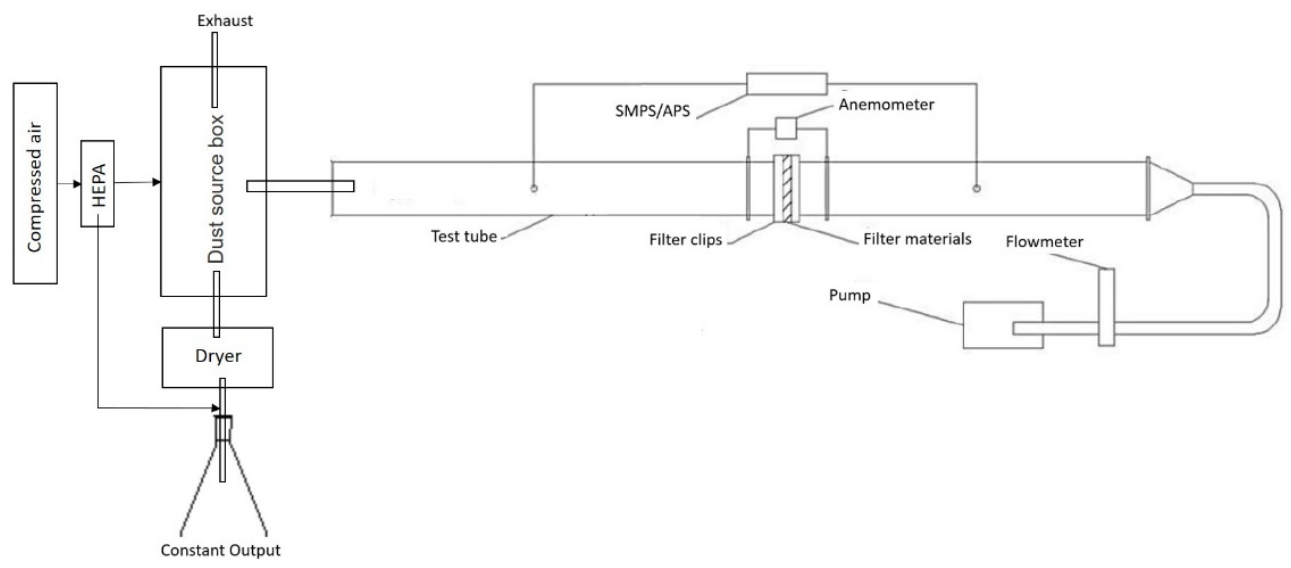

Figure 2. Schematic diagram of the filtration system for penetration rate testing.

By measuring the difference between the upstream and downstream particle counts, the penetration rate of the filter media with different particle sizes could be obtained.

$$
\text { Penetration rate }=1-E=C_{\text {out }} / C_{\text {in }} \times 100 \%
$$

where $E$ is the total collection efficiency of the filter media, and $C_{\text {in }}$ and $C_{\text {out }}$ represents the aerosol concentrations measured upstream and downstream of the filter media, respectively. A lower penetration rate value indicates more particles captured, and, therefore, better filter performance.

\section{Results and Discussion}

\subsection{Preparation of Nano-Encapsuled Phase Change Material with Silica Shell}

The nano-encapsulated phase change material within the silica shell (NPCMs) composite was synthesized with a silica precursor polymer-hyper-branched polyethoxysiloxane (PEOS) through a self-assembly method in mini-emulsion, as shown schematically in Figure 3. After emulsifying PCM and PEOS in hot water, the hyper-branched polyethoxysiloxane (PEOS) molecules tended to assemble at the PCM droplet interfaces due to its water insolubility and simultaneous pronounced amphiphilicity induced by hydrolysis at the oil/water interfaces. PEOS acted as a silica precursor polymer as well as an emulsion stabilizer during the assembly process. As the polymerization proceeds, PEOS macromolecules migrated continuously toward the oil/water interface drove by osmotic pressure 
and incompatibility [33]. Finally, PEOS was completely converted to a silica matrix on the PCM surface. The silica shell was formed to produce nano-encapsulated PCM.

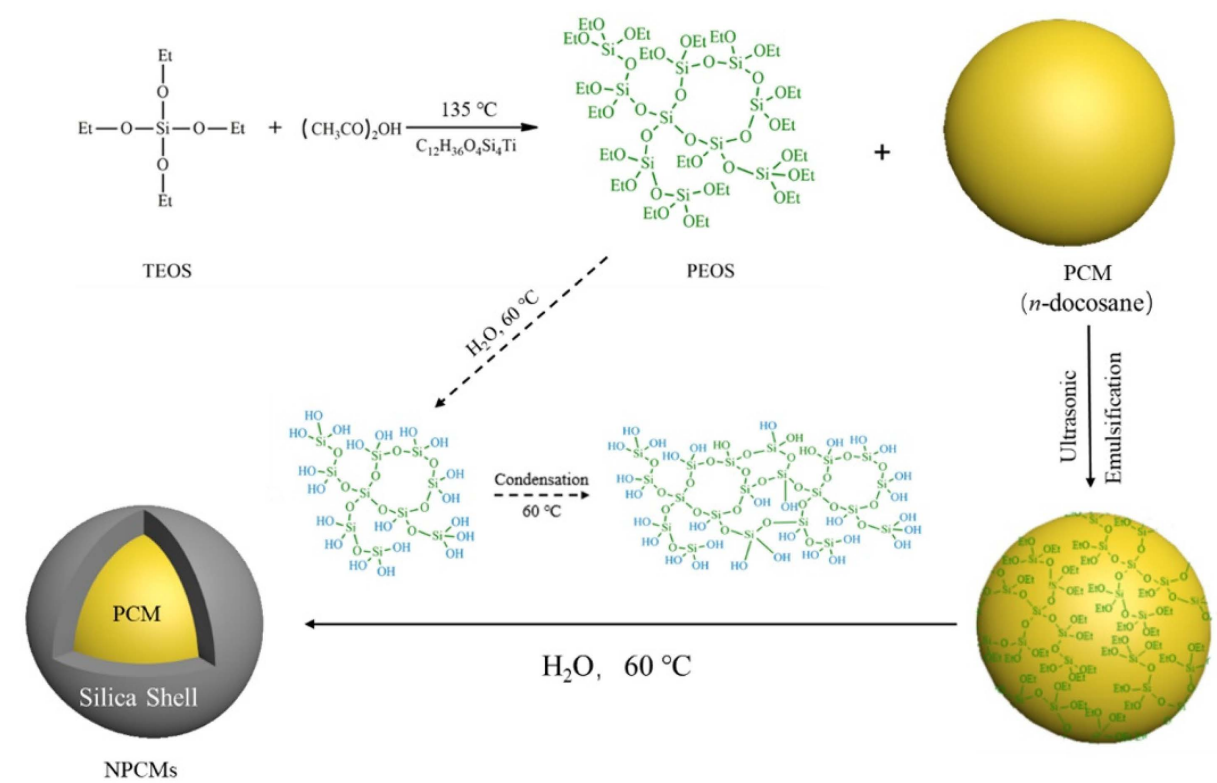

Figure 3. Schematic representation of the formation of silica nano-encapsuled PCM with PEOS by a self-assembly method in mini-emulsion.

The morphology of NPCMs was investigated by FESEM and TEM imaging. As shown in Figure 4a, monodisperse NPCMs had a perfect spherical shape with a mean diameter of $\sim 400 \mathrm{~nm}$ and a fragmentized capsule in insertion indicated the core-shell structure of NPCMs. Moreover, the well-defined core-shell structure with an average shell thickness of about $35 \mathrm{~nm}$ was confirmed by the TEM micrograph of the pure, hollow silica nanocapsules obtained by calcination in Figure $4 \mathrm{~b}$.

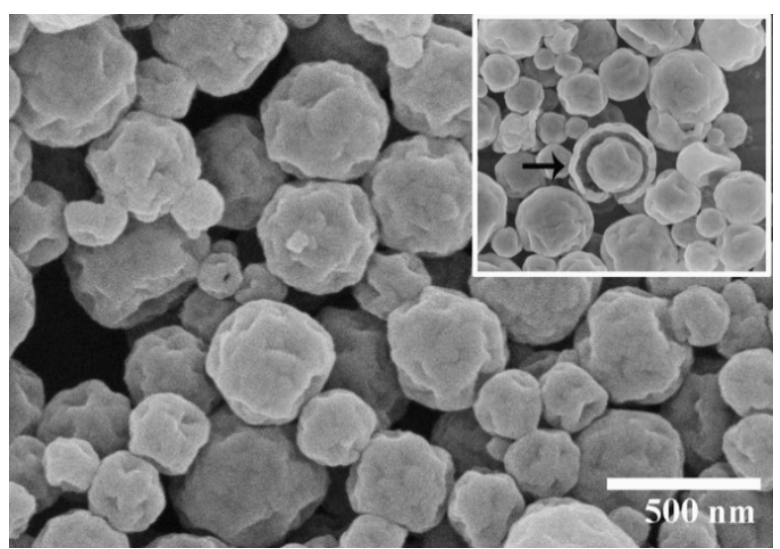

(a)

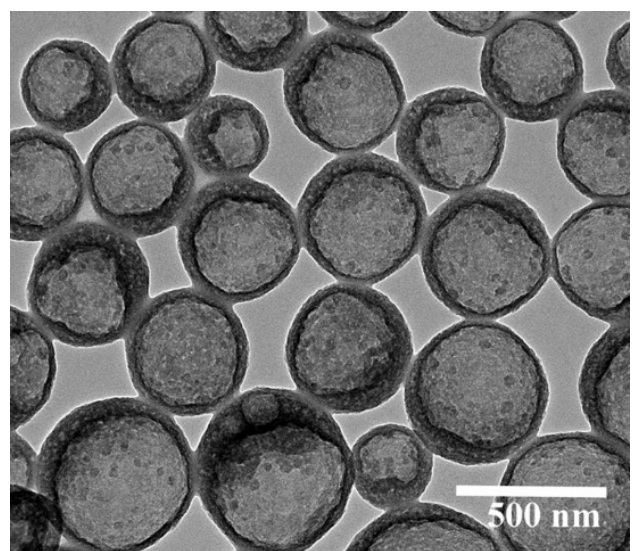

(b)

Figure 4. Morphology of nano-encapsuled PCMs with silica shell: (a) FE-SEM image and (b) TEM image.

The chemical compositions of NPCMs were characterized by FTIR (Figure 5). In the spectra of NPCMs, the characteristic bands at $1100 \mathrm{~cm}^{-1}, 800 \mathrm{~cm}^{-1}$, and $470 \mathrm{~cm}^{-1}$ were attributed to the Si-O-Si and Si-O of silica shells and absorption bands of C-H at $2930 \mathrm{~cm}^{-1}$ and $1470 \mathrm{~cm}^{-1}$ were attributed to the PCM core ( $n$-docosane), validating the existence of $\mathrm{n}$-docosane and silica in NPCMs. The spectrum of the PCM core was completely identical to that of pure $n$-docosane. In the spectrum of the shell, characteristic signals of PCM were invisible, confirming successful encapsulation of PCM. 
Thus, this self-assembly method via mini-emulsion based on hyper-branched polyethoxysiloxane (PEOS) for preparing silica encapsulating PCM was easy, efficient, and economically feasible.

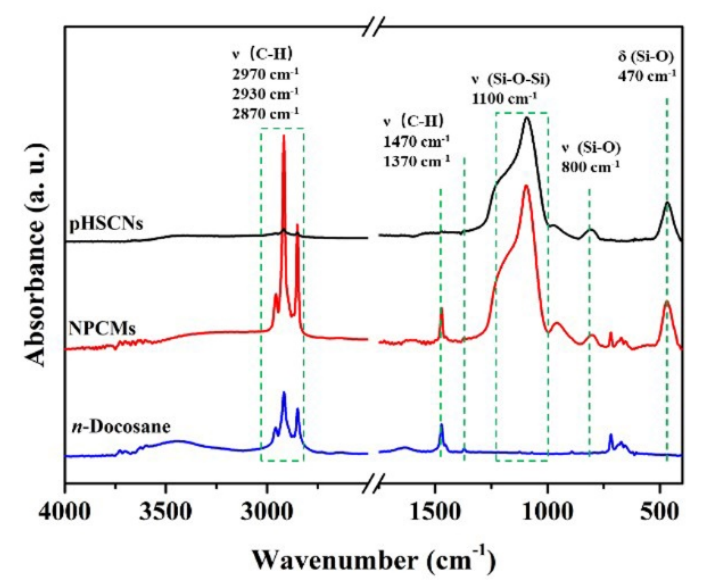

Figure 5. FTIR spectra of $n$-docosane (PCM), pure hollow silica nano-capsules shell (pHSCNs), and nano-encapsuled PCMs with silica shell (NPCMs).

\subsection{Thermal Stability of Nano-Encapsuled PCMs with Silica Shell}

The thermal stability and encapsulation capability of NPMS are critical to its performances, especially when they are utilized in a situation where thermal regulation is necessary. To investigate the above two properties of NPCMs, thermal gravimetric analysis (TGA) was employed. In Figure 6a, there was a typical one-step weight loss in the TGA curve of PCM and nothing was left at the end of $800^{\circ} \mathrm{C}$. The temperature of onset degradation and maximum decomposition rate for $\mathrm{PCM}$ were $162.29^{\circ} \mathrm{C}$ and $233.42^{\circ} \mathrm{C}$, respectively. In terms of pHSNCs, the only trivial weight loss at $138^{\circ} \mathrm{C}$ was attributed to the removal of humid water and loss of the loosely bonded absorbed water on silica nano-encapsule surface. By contrast, the two weight loss stages of NPCMs corresponded to the evaporation of water from the silica shell (about $5 \%$ ) and degradation of PCM in microcapsules, respectively. It could be deduced that about $65 \%$ NPCMs was encapsulated. The initial degradation temperature of NPCMs was approximately $200^{\circ} \mathrm{C}$, which is higher than that of PCM, indicating that the inert silica shell could act as a protective layer of the inner PCM. The thermal stability was markedly improved.

The significance of silica as an inorganic shell of NPCMs was not only to protect the encapsulated PCM at high temperature, but also the stable morphological structure calcinated at $500{ }^{\circ} \mathrm{C}$ for $2 \mathrm{~h}$, as shown in Figure $6 \mathrm{~b}$. That is to say, the super-solid silica shells endowed NPCMs with an outstanding stable microstructure and possible leakage of inner PCM at a high temperature was considerably avoided, significantly increasing the range of its applications. The leakage rate of NPCMs was measured as well [26]. NPCMs was heated at $150^{\circ} \mathrm{C}$ and was weighed after cooling to room temperature. No dramatic weight loss was observed, suggesting the good mechanical strength and barrier efficiency of the nano-capsule silica shell. 


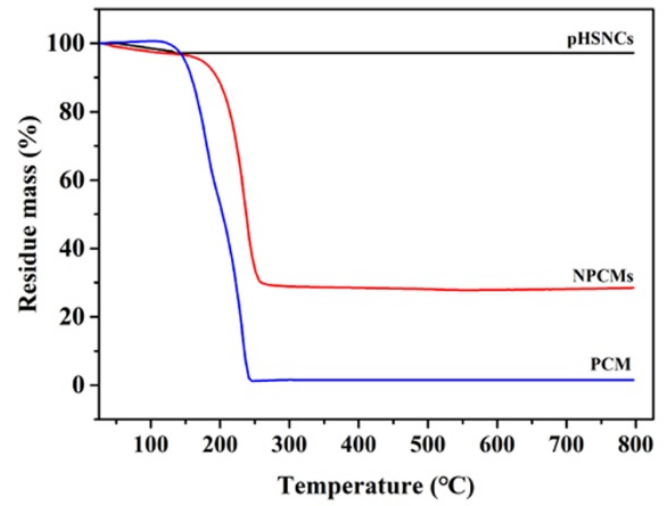

(a)

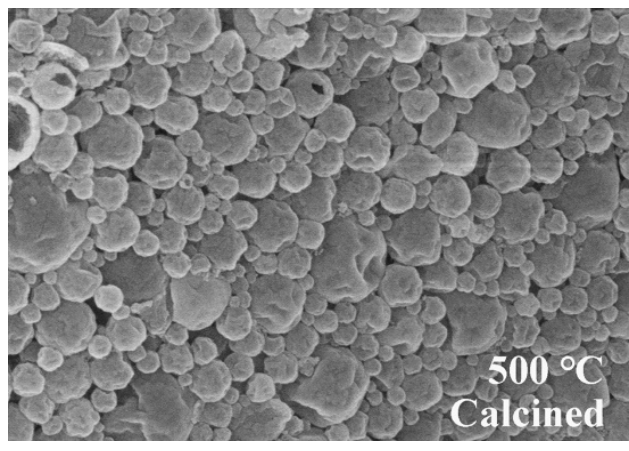

(b)

Figure 6. (a) TGA curves of PCM, pHSCNs, and NPCMs. (b) FE-SEM image of NPCMs after calcination at $500{ }^{\circ} \mathrm{C}$ for $2 \mathrm{~h}$.

\subsection{Microsture and Filtration Performance of Filter Media with NPCMs}

FE-SEM images of the filter media fabricated with NPCMs were presented in Figure 7, revealing the new microstructure of the filter medias. As shown in Figure 7, NPCMs assembly exhibited random distribution on the fiber surface of filter media as a shield layer, which was attributed to the deposition of NPCMs and interactions between NPCMs and polyurethane. The NPCMs' layer on filter media was increasingly dense, obvious, and rough, with an increasing amount of NPCMs. The morphology of fabricated filter media was remarkably changed by constructing nano-scale rough structures on the surface of filter media fibers. Thus, the effective contact area between dust particles and relevant fibers was significantly increased. It also could cut off from the environment by forming the NPCMs' layer on the fiber surface, which would enhance its resistance to the harsh industrial environment. Noteworthily, the dense and smaller-sized pores are distributed on the surface of the large filter media due to the density of filer media by increasing the concentration of NPCMs. The formatting of this structure was mainly ascribed to the nano-scale or sub-micro-scale fibrous network in the interstitial space of filter media by crosslinking between NPCMs and polyurethane. It would improve the filtration efficiency of filter media according to the capture mechanism of particles. The pore size of filter medias was measured in Table 1 . The mean pore size and the pore size distribution were shifted to a smaller value with the increase of NPCMs. The minimal mean pore size of filter media incorporating 30\% NPCMs was $1.98 \mu \mathrm{m}$, significantly smaller than that of control filter media $(15.43 \mu \mathrm{m})$ and filter media incorporating polyurethane $(12.23 \mu \mathrm{m})$.

The flow rate through the novel filter media would be lower by its competent microstructure, theoretically. However, what's actually happening is the co-act by filter media and the dust layer covering is the major role in influencing the flow rate through the actual operation. The results indicated that the novel filter media incorporating with NPCMs can meet the requirements of industrial flue gas dust removal. The penetration rate of filter media at standard flow rates was reduced from $457 \times 10^{-4} \%$ for control to $5 \times 10^{-4} \%$ for FM_NPCMs30, which are about two orders of magnitude lower, indicating filter media with significantly improved filtration efficiency was obtained. 

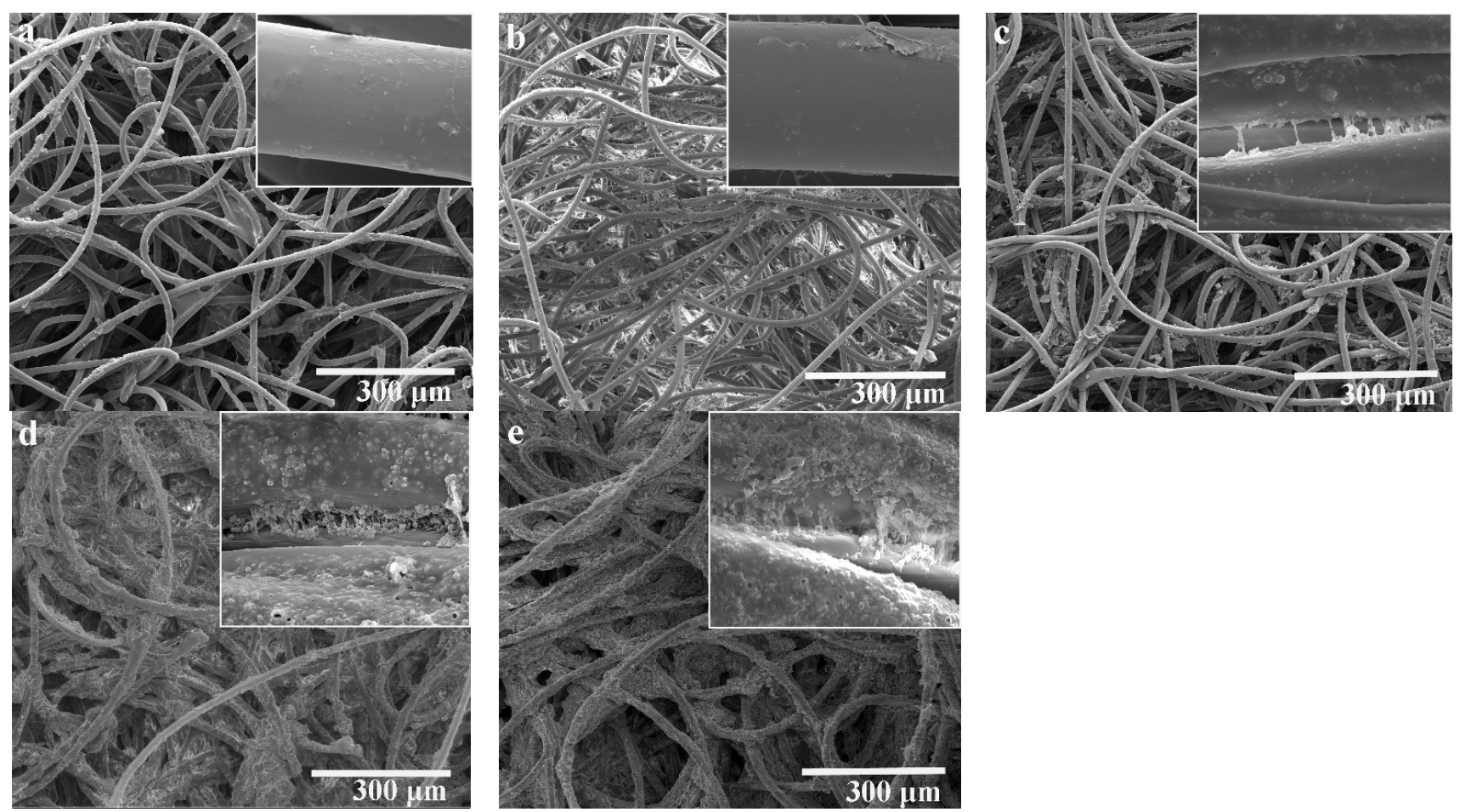

Figure 7. FE-SEM images of filter media: (a) FM, (b) FM_PU, (c) FM_NPCMs10, (d) FM_NPCMs20, and (e) FM_NPCMs30. The insets show the morphology of surface and fiber interstitial spaces for corresponding samples.

Table 1. The pore size and penetration rate of filter media.

\begin{tabular}{ccccccc}
\hline \multirow{2}{*}{ Sample } & Mean & Maximum & Minimum & $\begin{array}{c}\text { Standard } \\
\text { Deviation }\end{array}$ & $\begin{array}{c}\text { Penetration } \\
\text { Rate } \\
\left(\times \mathbf{1 0}^{-\mathbf{4} \%)}\right.\end{array}$ & $\begin{array}{c}\text { Standard } \\
\text { Deviation }\end{array}$ \\
\cline { 2 - 6 } & 15.43 & 43.79 & 4.62 & 5.64 & 457 & 31 \\
FM & 12.23 & 39.22 & 3.33 & 5.28 & 386 & 44 \\
FM_PU & 10.38 & 37.77 & 3.23 & 5.25 & 273 & 60 \\
FM_NPCMs10 & 28.49 & 1.40 & 4.83 & 81 & 37 \\
FM_NPCMs20 & 2.50 & 29.67 & 1.55 & 5.14 & 5 & 23 \\
FM_NPCMs30 & 1.98 & & & &
\end{tabular}

\subsection{Thermal Performance of Filter Media with NPCMs}

To evaluate the thermal performance of filter media with NPCMs, differential scanning calorimetry (DSC) of filter media was analyzed under a nitrogen atmosphere at a heating or cooling rate of $10^{\circ} \mathrm{C} / \mathrm{min}$, as shown in Figure 8. DSC curves of FM_NPCMs were similar to NPCMs, where the melting and crystallizing temperature of FM_NPCMs were close to NPCMs due to PCM encapsulates. Latent heat, characteristic of the amount of stored energy during the phase change, was determined. NPCMs exhibited a high storage capacity of thermal energy. The latent heat of melting and crystallizing were measured to be $6.07 \mathrm{~J} / \mathrm{g}$ and $3.95 \mathrm{~J} / \mathrm{g}$ for FM_NPCMs10, $22.84 \mathrm{~J} / \mathrm{g}$, and $16.06 \mathrm{~J} / \mathrm{g}$ for FM_NPCMs20, $58.75 \mathrm{~J} / \mathrm{g}$, and $52.84 \mathrm{~J} / \mathrm{g}$ for FM_NPCMs30, respectively. It was shown that higher NPCMs content in filter media led to higher latent heat storage. In contrast, there was no performance of thermal energy storage observed in control filter media and filter media with polyurethane due to the absence of NPCMs. These results indicate that NPCMs' fabricated filter media exhibited an advantage in thermal stability and heat capacity. In the practical situation, the surface temperature fluctuation of filter material in instantaneous thermal shock would be lowered and the corresponding thermal regulation and thermal resistance improved. 


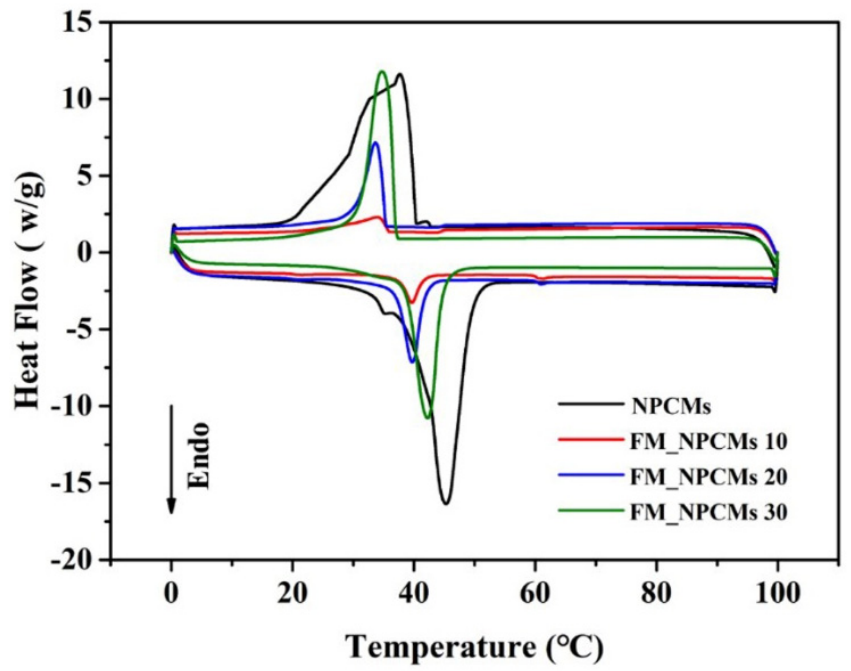

Figure 8. DSC curves of NPCM and the novel filter media incorporating with NPCMs.

The thermal regulation of NPCMs' fabricated filter media was evaluated by a temperature-time diagram and infrared thermography. There was little change about the thermal regulation of NPCMs' fabricated filter media before and after 100 thermal shock cycles with a simultaneous chemical exposure. As shown in Figure 9, the temperature lag of FM_NPCMs during the heating process occurred approximately from $40{ }^{\circ} \mathrm{C}$ to $90^{\circ} \mathrm{C}$, which corresponded to the phase transition temperature range of nano-encapsulated PCM. The surface temperature of FM_NPCMs was always lower than that of the control and the maximum temperature difference was up to $20^{\circ} \mathrm{C}$ in the phase transition temperature range at approximately $60{ }^{\circ} \mathrm{C}$, indicating the great thermal regulation performance of FM_NPCMs. This could be attributed to the thermal energy absorption of encapsulated PCM by melting during the heating process and low thermal conductivity of silica shells.

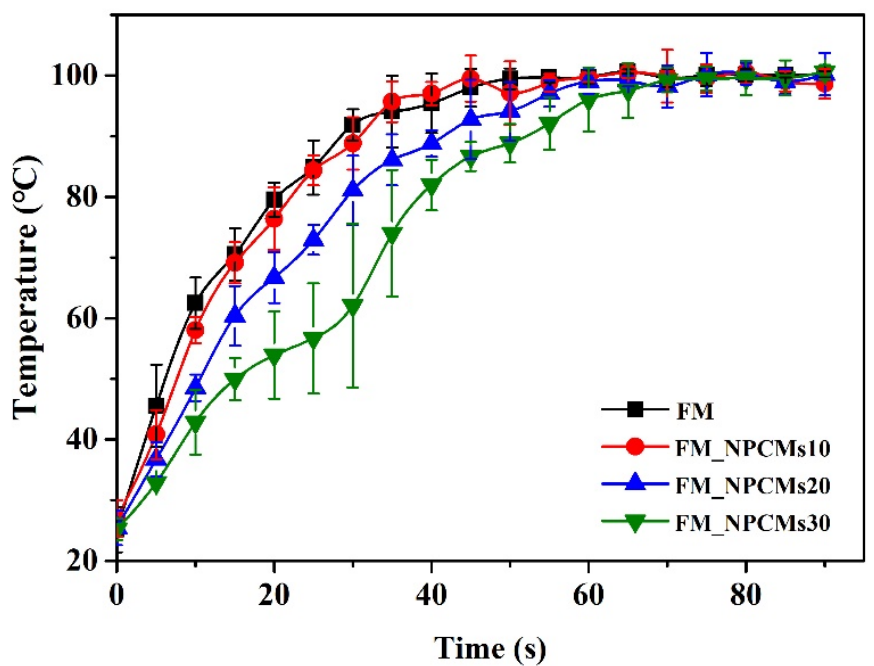

Figure 9. Time-dependent changes of the surface temperature of filter medias after thermal shock cycles with chemical exposure.

To visually demonstrate the thermal regulation performance, the temperature profile evolution of FM and FM_NPCMsS30 was captured by an infrared camera while being heated from bottom to top, after 100 thermal shock cycles with a simultaneous chemical exposure. Color in the images was the temperature indicator, i.e., the surface temperature of specimens. In Figure 10, as heating of the samples, a noticeable color difference from blue to red appeared in the thermographic images, indicating the increasing surface temperature 
of the heated samples, where the bigger the red part is, the higher the temperature of the samples is. At the beginning $(0 \mathrm{~s})$, samples were just placed on the heating plate. At $20 \mathrm{~s}$, it was clear that the red part of FM_NPCMs was smaller than that of the control, suggesting that the surface temperature of FM_NPCMs was lower than the control filter media at this moment. The reasons were that encapsulated PCM in the coating of FM_NPCMs melted to absorb heat and its thermal resistance was improved due to the silica shell of PCM. At $40 \mathrm{~s}$, there was still a minor difference in the red color between the control and FM_NPCMs. At $60 \mathrm{~s}$, the two images were almost similar, which was consistent with the temperature changes in Figure 8. Thus, filter media fabricated with NPCMs was endowed with temperature regulation and heat insulation to control the instantaneous fluctuation of temperature. FM_NPCMs has prospects in damage reduction caused by instantaneous thermal shock.
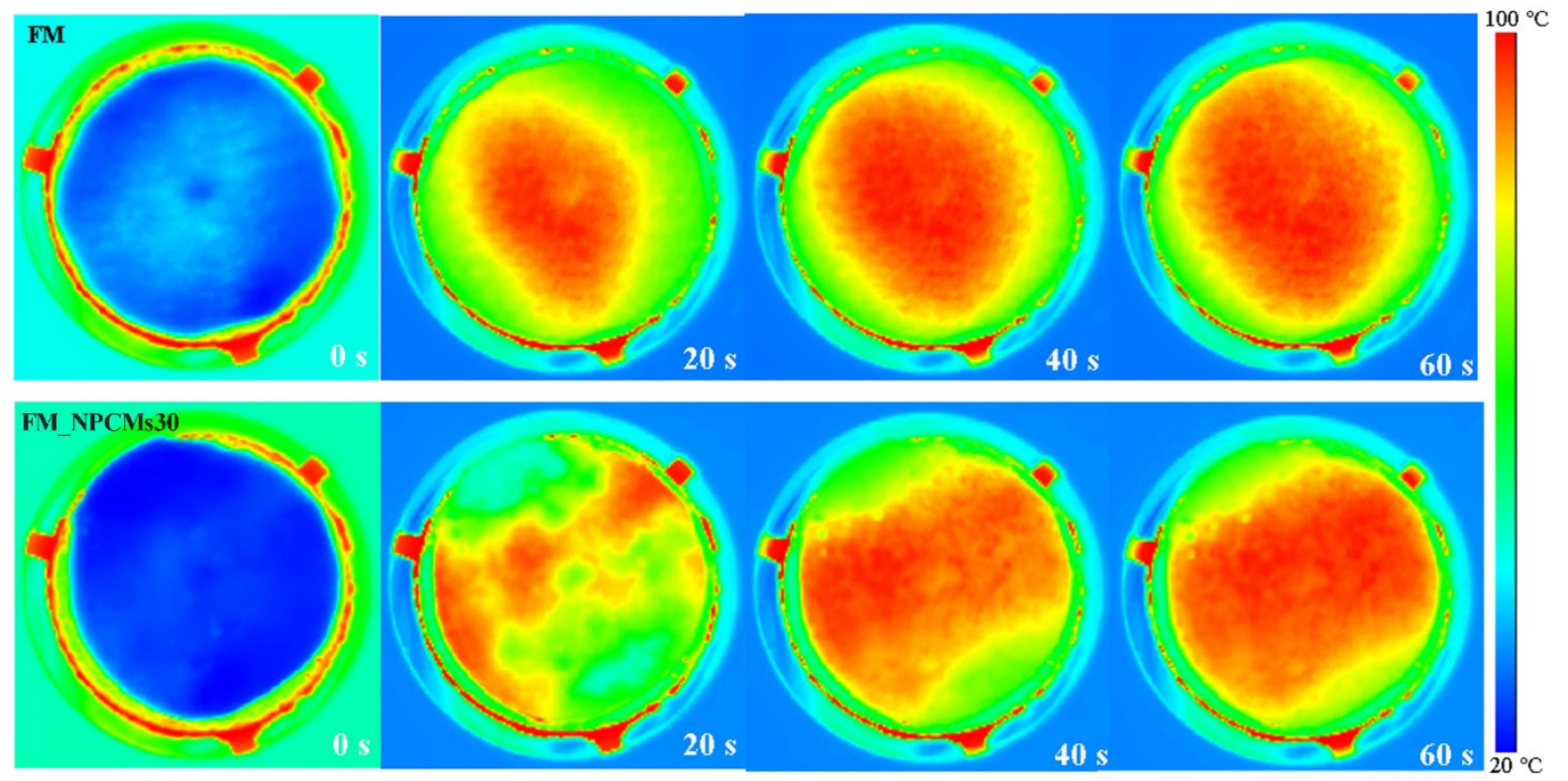

Figure 10. Infrared camera images of the original filter media (FM) and FM_NPCMs30.

\subsection{Environmental Endurance of Filter Media with NPCMs}

The tensile strength is an important factor to assess the environmental endurance of filter media, including resistance to instantaneous thermal shock and chemical erosion. In Figure 11, the tensile strength of filter media with different NPCMs' contents was displayed. FM was $1127.11 \mathrm{~N}$ and FM_NPCMs became enlarged with the increasing NPCMs on filter media, 1287.39 N for FM_NPCMs10, 1526.74 N for FM_NPCMs20, and 1633.27 N for FM_NPCMs30. There might be two reasons for the increased tensile strength of FM_NPCMs: the NPCM hybrid layer covering on fibers to strengthen filter media, fabricating more compact crosslinking networks among the fibers of filter media. Interpenetrating the composite NPCM and polyurethane in filter media could dissipate energy under the tensile property and improve the mechanical properties of filter media. However, the tensile strength of filter media was reduced to varying degrees after suffering various simulative working environments, such as thermal shock, chemical exposure, and thermal shock with chemical exposure. The tensile strength's loss of filter media was limited by incorporating NPCM, and the more NPCMs coating on filter media is, the lower the tensile strength loss is. Approximately $37.58 \%$ of tensile strength reduction was observed for the control sample FM after 100 thermal shock cycles with chemical exposure and $27.31 \%$, $25.18 \%$, and 20.37\% for FM_NPCMs10, FM_NPCMs20, and FM_NPCMs30, respectively. In FM_NPCMs, NPCMs could absorb transient heat caused by thermal shock and lower the effect of thermal fluctuation on the filter material. At the same time, the isolation of dense inert core-shell silica NPCMs' layer effectively protected filter media against the 
chemical environment. Thermoregulation and insulation functions of the NPCM layer on FM_NPCMs was a major trigger to reduce damages in a harsh environment.

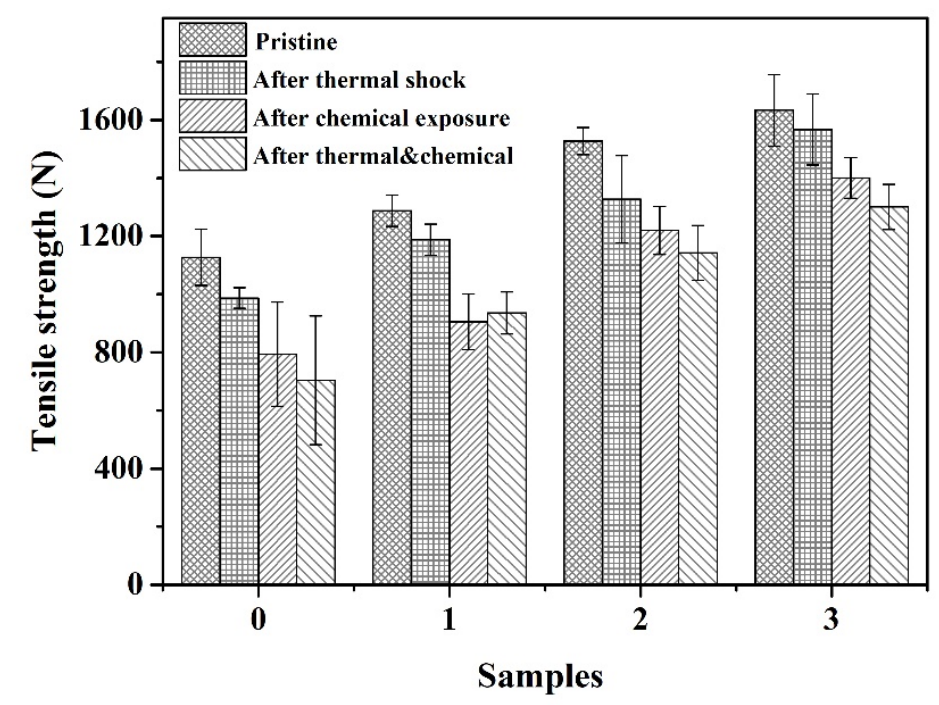

Figure 11. Tensile strength of filter medias before and after the thermal shock cycles with simultaneous chemical exposure. (0\#: FM; 1\#:FM_NPCMs10,2\#:FM_NPCMs20,3\#:FM_NPCMs30).

\section{Conclusions}

In this work, a novel filter media fabricated with silica nano-encapsulated phase change material (NPCMs) has been proposed by a dip-dry-cure process, with the aim to develop filter media with thermal regulation and excellent environmental endurance to be utilized for air dispersion control in the power plant industry.

The core-shell nanoparticles' NPCMs, as core components of novel filter media fabricated, has been developed simply by emulsifying hyper-branched polyethoxysiloxanes (PEOS), a silica shell precursor, emulsion stabilizer, and PCM mixture in water. FTIR and SEM results of NPCMs confirmed that PCM was successfully encapsulated into the silica shell and NPCMs exhibited a regular sphere. TGA of NPCMs revealed its excellent thermal stability due to the silica shell. Even being calcined at $500{ }^{\circ} \mathrm{C}$, the morphology of NPCMs remained unchanged and almost no leakage of PCM core material was observed due to the protection of the intact silica shell with excellent thermal stability.

The novel filter media incorporated with NPCMs were systematically analyzed. SEM images of fabricated filter media demonstrated that the microstructure of filter media was greatly changed, where NPCMs formed a functional layer wrapping fibers of filter media and filling in space among fibers. The mean pore size of filter media was reduced from $15.43 \mu \mathrm{m}$ to $1.98 \mu \mathrm{m}$, and the corresponding penetration rate was decreased by two orders of magnitude, which is indicative of better capture capability of the novel filter media. With the increasing loading of NPCMs in filter media, the latent heat of melting and crystallizing in DSC of filter media was growing as well as an increasingly clear temperature lag after 100 thermal shock cycles with chemical exposure in the heating-up process. Thus, increasingly better thermal regulation of the fabricated filter media was obtained. In addition, a good temperature-regulated property of the fabricated filter media was studied by infrared thermography, which could provide a substantial improvement of the thermal regulation and thermal resistance of the novel filter media.

The mechanical property of filter media under harsh environments was greatly enhanced as a result of fabrication with NPCMs. The tensile strength was reduced by $37.58 \%$ for the control and $20.37 \%$ for the filter media by incorporating NPCMs after suffering 100 thermal shock cycles with chemical exposure.

Accordingly, we believe that this study has proposed a versatile method to fabricate a novel filter media with combined thermal regulation, environmental endurance, and high 
filtration efficiency. This novel filter media incorporating with core shell nano-encapsulated phase change material could have a potential for industrial air application, extend its lifespans, and enhance operation stability.

Author Contributions: Conceptualization, C.Z. and J.L. Formal analysis, S.C. Investigation, G.S. Resources, H.S. Writing-original draft preparation, C.Z. Writing-review and editing, J.L. Supervision, C.Z. Funding acquisition, C.Z. All authors have read and agreed to the published version of the manuscript.

Funding: This research was funded by natural science foundation for young scientists of Zhejiang province, grant number LQ17B060005, and natural key research and development program of China, grant number 2018YFC0705300.

Institutional Review Board Statement: Not applicable.

Informed Consent Statement: Not applicable.

Data Availability Statement: The data presented in this study are available on request from the corresponding author.

Acknowledgments: C.Z. would like to acknowledge the Ministry of Science and Technology of the People's Republic of China and Natural Science Foundation of Zhejiang Province for the financial support. The authors acknowledge Donghua University, Jiaxing University, and Sippr Engineering Group Co., LTD for the logistical support.

Conflicts of Interest: The authors declare no conflict of interest.

\section{References}

1. $\quad$ Lin, J.-H.; Huang, C.-L.; Li, T.-T.; Lee, Y.-M.; Wu, Z.-H.; Lou, C.-W. Extended PTFE fabrics used as high-temperature filter clothes: Manufacturing technique and chemical stability evaluation. J. Text. Inst. 2015, 106, 793-799. [CrossRef]

2. Boudhan, R.; Joubert, A.; Durécu, S.; Gueraoui, K.; Le Coq, L. Influence of air humidity on particle filtration performance of a pulse-jet bag filter. J. Aerosol. Sci. 2019, 130, 1-9. [CrossRef]

3. Kurtz, O.; Meyer, J.; Kasper, G. Influence of filter operating parameters on fine dust emissions from pulse-cleaned filter bags. Chem. Eng. Technol. 2016, 39, 435-443. [CrossRef]

4. Wang, A.; Song, Q.; Tu, G.; Wang, H.; Yue, Y.; Yao, Q. Influence of flue gas cleaning system on characteristics of $\mathrm{PM}_{2.5} \mathrm{emission}$ from coal-fired power plants. Int. J. Coal Sci. Technol. 2014, 1, 4-12. [CrossRef]

5. Patnaik, A.; Anandjiwala, R.D. Reasons for filter bag failure and method development to improve its life span. Chem. Eng. Technol. 2016, 39, 529-534. [CrossRef]

6. Díez-Pascual, A.M.; Naffakh, M. Synthesis and characterization of nitrated and aminated poly(phenylene sulfide) derivatives for advanced applications. Mater. Chem. Phys. 2012, 131, 605-614. [CrossRef]

7. Ye, Y.; Wang, Z. Effect of corona discharge on polyphenylene sulfide filter material of electrostatic-bag composite precipitators. Ind. Eng. Chem. Res. 2018, 57, 1319-1330. [CrossRef]

8. Wang, C.-T.; Lee, S.-T.; Li, L.-Y.; Syu, J.-Y.; Kuo, C.-C.; Lin, W.-Y. A Novel Charged Fibrous Media Characterized by Higher Efficiency and Lower Pressure Drop. Aerosol. Sci. Technol. 2019, 53, 1441-1452. [CrossRef]

9. Liu, Y.-S.; Qian, X.-M.; Wang, L.; Qian, Y.; Bai, H.; Wang, X.-B. Hierarchical micro/nanofibrous filter for effective fine-particle capture. Powder Technol. 2020, 360, 1192-1199. [CrossRef]

10. Li, X.-Q.; Wang, N.; Fan, G.; Yu, J.-Y.; Gao, J.; Sun, G.; Ding, B. Electreted polyetherimide-silica fibrous membranes for enhanced filtration of fine particles. J. Colloid Interface Sci. 2015, 439, 12-20. [CrossRef]

11. Su, J.-F.; Yang, G.-H.; Cheng, C.-L.; Huang, C.; Xu, H.; Ke, Q.-F. Hierarchically structured $\mathrm{TiO}_{2} / \mathrm{PAN}$ nanofibrous membranes for high-efficiency air filtration and toluene degradation. J. Colloid Interface Sci. 2017, 507, 386-396. [CrossRef]

12. Bortolassi, A.C.C.; Nagarajan, S.; Lima, B.D.A.; Guerra, V.G.; Aguiar, M.L.; Huon, V.; Soussan, L.; Cornu, D.; Miele, P.; Bechelany, M. Efficient nanoparticles removal and bactericidal action of electrospun nanofibers membranes for air filtration. Mat. Sci. Eng. C Mater. 2019, 102, 718-729. [CrossRef] [PubMed]

13. Lu, X.; Sun, Y.; Chen, Z.; Gao, Y. A multi-functional textile that combines self-cleaning, water-proofing and $\mathrm{VO}_{2}$-based temperatureresponsive thermoregulating. Sol. Energy Mater. Sol. Cells 2017, 159, 102-111. [CrossRef]

14. Zhou, D.; Zhao, C.Y.; Tian, Y. Review on thermal energy storage with Phase change materials (PCMs) in building applications. Appl. Energy 2012, 92, 593-605. [CrossRef]

15. Xie, J.; Wang, W.; Liu, J.; Pan, S. Thermal performance analysis of PCM components heat storage using mechanical ventilation: Experimental results. Energy Build 2016, 123, 169-178. [CrossRef]

16. Seong, Y.-B.; Energies, J.-H.L.J. Energy saving potentials of phase change materials applied to lightweight building envelopes. Energies 2013, 6, 5219-5230. [CrossRef] 
17. Dincer, I.; Dost, S. A perspective on thermal energy storage systems for solar energy applications. Int. J. Energy Res. 1996, 20, 547-557. [CrossRef]

18. Koca, A.; Oztop, H.F.; Koyun, T.; Varol, Y. Energy and exergy analysis of a latent heat storage system with phase change material for a solar collector. Renew. Energy 2008, 33, 567-574. [CrossRef]

19. Sarier, N.; Onder, E. Organic phase change materials and their textile applications: An overview. Thermochim. Acta 2012, 540, 7-60. [CrossRef]

20. Sun, D.; Iqbal, K. Synthesis of functional nanocapsules and their application to cotton fabric for thermal management. Cellulose 2017, 24, 3525-3543. [CrossRef]

21. Iqbal, K.; Sun, D. Synthesis of nanoencapsulated Glauber's salt using PMMA shell and its application on cotton for thermoregulating effect. Cellulose 2018, 25, 2103-2113. [CrossRef]

22. Lu, P.; Chen, W.; Fan, J.; Ghaban, R.; Zhu, M. Thermally triggered nanocapillary encapsulation of lauric acid in polystyrene hollow fibers for efficient thermal energy storage. ACS Sustain. Chem. Eng. 2018, 6, 2656-2666. [CrossRef]

23. Zhang, G.H.; Bon, S.A.F.; Zhao, C.Y. Synthesis, characterization and thermal properties of novel nanoencapsulated phase change materials for thermal energy storage. Sol. Energy 2012, 86, 1149-1154. [CrossRef]

24. Su, J.-F.; Huang, Z.; Ren, L. High compact melamine-formaldehyde microPCMs containing n-octadecane fabricated by a two-step coacervation method. Colloid Polym. Sci. 2007, 285, 1581-1591. [CrossRef]

25. Kahraman Döğüşcü, D.; Kızıl, Ç.; Biçer, A.; Sarı, A.; Alkan, C. Microencapsulated n-alkane eutectics in polystyrene for solar thermal applications. Sol. Energy 2018, 160, 32-42. [CrossRef]

26. Jiang, Z.; Yang, W.; He, F.; Xie, C.; Fan, J.; Wu, J.; Zhang, K. Modified phase change microcapsules with calcium carbonate and graphene oxide shells for enhanced energy storage and leakage prevention. ACS Sustain. Chem. Eng. 2018, 6, 5182-5191. [CrossRef]

27. Tang, F.; Liu, L.; Alva, G.; Jia, Y.; Fang, G. Synthesis and properties of microencapsulated octadecane with silica shell as shape-stabilized thermal energy storage materials. Sol. Energy Mater. Sol. Cells 2017, 160, 1-6. [CrossRef]

28. Ciriminna, R.; Sciortino, M.; Alonzo, G.; Schrijver, A.D.; Pagliaro, M. From molecules to systems: Sol-gel microencapsulation in silica-based materials. Chem. Rev. 2011, 111, 765-789. [CrossRef] [PubMed]

29. Zhang, C.; Yan, K.-L.; Hu, C.-Y.; Zhao, Y.-L.; Chen, Z.; Zhu, X.-M.; Möller, M. Encapsulation of enzymes in silica nanocapsules formed by an amphiphilic precursor polymer in water. J. Mater. Chem. B 2015, 3, 1261-1267. [CrossRef] [PubMed]

30. Liang, S.; Li, Q.; Zhu, Y.; Chen, K.; Tian, C.; Wang, J.; Bai, R. Nanoencapsulation of $n$-octadecane phase change material with silica shell through interfacial hydrolysis and polycondensation in miniemulsion. Energy 2015, 93, 1684-1692. [CrossRef]

31. Paneliya, S.; Khanna, S.; Singh, A.P.; Patel, Y.K.; Vanpariya, A.; Makani, N.H.; Banerjee, R.; Mukhopadhyay, I. Core shell paraffin/silica nanocomposite: A promising phase change material for thermal energy storage. Renew. Energy 2021, 167, 591-599. [CrossRef]

32. Zhu, X.-M.; Jaumann, M.; Peter, K.; Möller, M.; Melian, C.; Adams-Buda, A.; Demco, D.E.; Blümich, B.J.M. One-pot synthesis of hyperbranched polyethoxysiloxanes. Macromolecules 2006, 39, 1701-1708. [CrossRef]

33. Zhao, Y.-L.; Liu, J.; Chen, Z.; Zhu, X.-M.; Möller, M. Hybrid nanostructured particles via surfactant-free double miniemulsion polymerization. Nat. Commun. 2018, 9, 1918. [CrossRef] [PubMed]

34. Chen, Z.; Zhao, Y.-L.; Zhao, Y.; Thomas, H.; Zhu, X.-M.; Möller, M. Inclusion of phase-change materials in submicron silica capsules using a surfactant-free emulsion approach. Langmuir 2018, 34, 10397-10406. [CrossRef] [PubMed] 